\title{
The Analysis based on the Internal Marketing Hotel Employee Satisfaction
}

\author{
Ziwei Huang \\ College of Economics and Management, \\ Hebei University of Science and Technology, \\ Shijiazhuang 050018, China \\ 983789127@qq.com
}

\begin{abstract}
With the development of social economy, the competition between the enterprises is becoming more and more fierce. The status of employees in the enterprise is more and more important, this leads to the increasing demand for internal marketing research. This paper took hotel industry as examples, surveyed four hotels, and offered a questionnaire investigation to the four hotels. First of all, this article discussed the importance of the hotel internal employee satisfaction from the internal marketing theory, then established the six relevant indicators and then used the gray comprehensive evaluation method to analyze the results, finally got the degree of satisfaction of the four hotels'staff and found out relevant solutions so as to improve the satisfaction of the hotels'employees.
\end{abstract}

Keywords- internal marketing; the satisfaction of staff; hotel; gray comprehensive evaluation

\section{INTRODUCTION}

The competition in present market environment is very fierce. Our country also will join into the developmentoriented society gradually, the third industry will rise to the dominant position. In recent years, the number of the people that engage in the service sector have already amounted to sixty percent of total employment in China , the output value has reached forty percent of GDP. This shows that the service industry has also occupies a pivotal position in the national income.

In the modern enterprise, especially service enterprises, who has the more and better customer resources than its rivals, who will have more chances of winning the competition.However,in abroad, many companies do the management work excellently, the leaders believe that customer relationship can react by employees relationship, employees satisfaction is the premise of customer satisfaction. The companies only have the satisfactory employees firstly, just can have quality services that provide higher efficiency and benefit for external customers, eventually produce satisfied customers. Therefore, the status of employees in the enterprise are more and more important, this leads to the increasing demand for internal marketing research.

\section{THE MEANING AND EFFECT OF INTERNAL MARKETING}

Internal marketing is that the organization treat employ ees as internal customers and try to satisfy the demand of e

\author{
Lei Wang \\ College of Economics and Management, \\ Hebei University of Science and Technology, \\ Shijiazhuang 050018, China \\ 570743932@qq.com
}

mployees, and promote organization policy and the organi zation itself to employees, make it able to participate in ser vice according to marketing purposes. Its core is how to de velop employees that have customer awareness. Its goal is to encourage the establishment of efficient service marketi ng system, build the organization members can create "the real customers" environment space for the enterprise.

The influence of employee satisfaction to enterprise's $p$ rofit is obvious, if the employee satisfaction increase, it ca $\mathrm{n}$ better meet customer demand and provide customers wit $\mathrm{h}$ quality service ,then customer satisfaction and loyalty im proves. This will make the enterprise profit grow , and let $t$ he profitability increase. To increase employee satisfaction requires enterprises to deliver employees high-quality inte rnal service quality and carry out the internal marketing. T hus, improving employee satisfaction has become top prio rity of the internal marketing.

The hotel is a typical service industry. So, carrying out the hotel internal employee satisfaction survey is the premi se of putting forward effective internal marketing strategy and improving service quality.

\section{THE IMPLEMENTATION OF THE GRAY CORRELATION EVALUATION METHOD}

Gray correlation evaluation method is based on gray rel ational analysis method. Its purpose is revealing the main $r$ elationship among various factors that can result in the cha nge of phenomenon through a certain method, finding out the important factors influencing the target value, making $t$ he "gray" relationship between various factors cleared. In $t$ he evaluation of enterprise technology innovation ability, s tatistics caliber is not completely consistent because of the large amount of data collection, therefore, using the gray correlation evaluation method is appropriate. Specific eval uation procedure is:

\section{A. Finish the basic data of evaluation index system, construct the original matrix.}

If there are i evaluation objects, each evaluation object has a $\mathrm{j}$ evaluation index. The original matrix $\mathrm{X}$ could be co nstructed in this way: 
$X=\left[\begin{array}{cccc}x_{11} & x_{12} & \cdots & x_{1 j} \\ x_{21} & x_{22} & \cdots & x_{2 j} \\ \vdots & \vdots & & \vdots \\ x_{i 1} & x_{i 2} & \cdots & x_{i j}\end{array}\right]$

$(i=1,2, \cdots, i) ;(j=1,2, \cdots, j)$

B. The dimensionless of evaluation index

Let index dimensionless process the improved efficacy coefficient method, the formula is:

$$
a_{i j}=\left(x_{i j}-\min x_{i j}\right) /\left(\max x_{i j}-\min x_{i j}\right) \times 0.6+0.4
$$

C. Determine the reference sequence $a_{0}$

$$
a_{0}=\{1,1, \cdots, 1\}
$$

D. The biggest difference for two level $\Delta(\max )$ and the least difference for two level $\Delta(\mathrm{min})$

$\Delta(\max )=\max _{1 \leq i \leq m} \max _{1 \leq j \leq n}\left(\Delta_{i j}\right) ; \Delta(\min )=\min _{1 \leq i \leq m} \min _{1 \leq j \leq n}\left(\Delta_{i j}\right) E$.

Calculate correlation coefficient $\xi_{i j}$

Reflect the close degree of two series in a certain period, the formula is:

$$
\xi_{i j}=[\Delta(\min )+\rho \Delta(\max )] /\left[\Delta_{i j}+\rho \Delta(\max )\right]
$$

$\rho$ is the distinguish coefficient, and taken between 0.1 and 0.5 generally, this study takes it as 0.5 on the basis of repeated trial.

\section{F. Calculate the correlation of sheer level.}

The important degree of the various index is different, so the correlation method let the weight be multiplied by the coefficient of correlation. This article uses the analytic hierarchy process (AHP) to get the priority weights as follows:

$W=\left(w_{1}, \quad w_{2}, \cdots, \quad w_{j}\right)$

The evaluation scores $E_{i}$ formula:

$E_{i}=\sum_{j=1}^{n} w_{j} \xi_{i j} \times 100$

G. Calculate the final correlation of multi-layer evaluation system

The correlation coefficient of each index level $\mathrm{K}$ synthesis, were they belong on a layer of k-1 layer index correlation; and then a layer of the degree of association as the original data, to synthesize the index layer K-2 correlation, and so on, until the top index the correlation.

\section{THE ESTABLISHMENT AND IMPLEMENTATION OF EMPLOYEE SATISFACTION INDEX SYSTEM}

\section{A. The principle of index system building}

The evaluation of hotel staff satisfaction should follow the following principles: (1) The scientific principle, the evaluation of the index must have a theoretical basis, can reflect the feeling of hotel staff. (2) The system principle, the hotel staff satisfaction should be evaluated from the perspective of system. The evaluation employee satisfaction index system should reflect and measure the main characteristics in evaluation system as an organic whole, contains the comprehensive elements in various aspects. (3) Scalability principle, the quantitative numbers of evaluation index is the key to the evaluation of hotel employee satisfaction research. The hotel employee satisfaction that is based on the measurements should be the quantitative numerical values, so when we construct the index system, the choice of the indicators must be able to conduct statistics, analysis and calculation, to meet the scalability principles .

\section{B. Evaluation index system}

In this paper, we through the form of a questionnaire to survey, divide into A, B, C, D four hotels. Involving six indicators, let the employees evaluate the satisfaction of these six factors. Each factor'score is divided between 0 and 10. The higher satisfaction, the higher score. To the original score, we statistics a composite scores on the evaluation factors by using the weighted average method. Six indicators are corporate culture, salary and welfare, training, participation in management, communication, development.

These six factors are very important on the stability and development of an enterprise, so let employees scoring on these six factors. We issued 200 papers, recovered 195, 180 copies are effective. On this basis, this paper use statistical analysis software SPSS to analyze the collected data.

TABLE I. The Score of Employee Satisfaction

\begin{tabular}{|c|c|c|c|c|c|c|}
\hline Hotel & $\begin{array}{c}\text { corpo } \\
\text { rate } \\
\text { cultu } \\
\text { re }\end{array}$ & $\begin{array}{c}\text { salary } \\
\text { and } \\
\text { welfar } \\
\text { e }\end{array}$ & $\begin{array}{c}\text { trainin } \\
\text { g }\end{array}$ & $\begin{array}{c}\text { partici } \\
\text { pation } \\
\text { in } \\
\text { manag } \\
\text { ement }\end{array}$ & $\begin{array}{c}\text { commu } \\
\text { nicatio } \\
\mathbf{n}\end{array}$ & $\begin{array}{c}\text { develo } \\
\text { pment }\end{array}$ \\
\hline A & 7 & 4 & 6 & 5 & 7 & 4 \\
\hline B & 7 & 6 & 7 & 6 & 8 & 5 \\
\hline C & 8 & 4 & 7 & 4 & 6 & 5 \\
\hline D & 6 & 5 & 8 & 5 & 7 & 6 \\
\hline $\begin{array}{c}\text { The } \\
\text { optimal } \\
\text { referen } \\
\text { ce } \\
\text { sequenc } \\
\text { e }\end{array}$ & 8 & 6 & 8 & 6 & 8 & 6 \\
\hline
\end{tabular}

Through expert consultation and the method of AHP, we determine the weight of each evaluation factor, then we get the table below:

TABLE II. WEIGHTS OF EACH INDEX

\begin{tabular}{|c|c|c|c|c|c|c|}
\hline $\begin{array}{c}\text { Indica } \\
\text { tors }\end{array}$ & $\begin{array}{c}\text { Corpo } \\
\text { rate } \\
\text { Cultur } \\
\text { e }\end{array}$ & $\begin{array}{c}\text { Salary } \\
\text { and } \\
\text { Welfar } \\
\text { e }\end{array}$ & $\begin{array}{c}\text { Traini } \\
\text { ng }\end{array}$ & $\begin{array}{c}\text { Partici } \\
\text { pation } \\
\text { in } \\
\text { Manag } \\
\text { ement }\end{array}$ & $\begin{array}{c}\text { Comm } \\
\text { unicati } \\
\text { on }\end{array}$ & $\begin{array}{c}\text { Develo } \\
\text { pment }\end{array}$ \\
\hline The & 0.0402 & 0.3037 & 0.1856 & 0.1126 & 0.1788 & 0.1788 \\
weight & 644596 & 506987 & 238377 & 666587 & 471725 & 47172 \\
& 596807 & 21142 & 88134 & 1121 & 59916 & 55992 \\
\hline
\end{tabular}


Through statistical analysis software SPSS, we get each index correlation and pros ,as the following table:

TABLE III. INDEX CORRELATION AND PROS

\begin{tabular}{c|c|c|c|c}
\hline $\begin{array}{c}\text { The } \\
\text { underlying } \\
\text { index }\end{array}$ & Hotel A & Hotel B & Hotel C & Hotel D \\
\hline $\begin{array}{c}\text { corporate } \\
\text { culture, }\end{array}$ & 0.5 & 0.5 & 1 & 0.3333 \\
\hline $\begin{array}{c}\text { salary and } \\
\text { welfare }\end{array}$ & 0.3333 & 1 & 0.3333 & 0.5 \\
\hline $\begin{array}{c}\text { training } \\
\text { participati } \\
\text { on in } \\
\text { manageme } \\
\text { nt }\end{array}$ & 0.3333 & 0.5 & 0.5 & 1 \\
\hline $\begin{array}{c}\text { communic } \\
\text { ation }\end{array}$ & 0.5 & 1 & 0.3333 & 0.5 \\
\hline $\begin{array}{c}\text { developme } \\
\text { nt }\end{array}$ & 0.3333 & 0.5 & 0.5 & 1 \\
\hline $\begin{array}{c}\text { correlation } \\
\text { R }\end{array}$ & 0.3886 & 0.7976 & 0.4209 & 0.6755 \\
\hline $\begin{array}{c}\text { sort the list } \\
\text { by } \\
\text { relational } \\
\text { degree }\end{array}$ & 4 & 1 & 3 & 2 \\
\hline $\begin{array}{c}\text { note: biggest gray } \\
\text { nom }\end{array}$ & 0.5 & & \\
\hline
\end{tabular}

note: biggest gray correlation evaluation objects is the best

\section{THE EVALUATION AND ANALYSIS OF EACH HOTEL EMPLOYEE SATISFACTION}

Through the above calculation results we can see that the gray correlation degree sequence of hotel staff satisfaction is $r_{B} \succ r_{D} \succ r_{C} \succ r_{A}$, we can see that the B hotel staff satisfaction is higher than D hotel staff satisfaction, the D hotel staff satisfaction is higher than $\mathrm{C}$ hotel staff satisfaction, the $\mathrm{C}$ hotel staff satisfaction is higher than A hotel staff satisfaction.

Hotel B has good salary and welfare relatively, and its internal staff have a good communication environment, they can also be positive to participate in the hotel's internal management relatively, these three factors are very critical for a hotel. So the hotel B staff satisfaction is highest. Hotel D also has a satisfactory „salary and welfare relatively, and hotel D do the training work for internal staff relatively well, and the staff are satisfied for their future development space relatively, but it's clear that the employees satisfaction of the hotel enterprise culture is not high. So the D hotel staff satisfaction is lower than B comprehensively. The hotel C whose employees' satisfaction ranked third, the staff of this hotel identify with its hotel cultural, but dissatisfied with the salary and welfare, and the hotel staff is lack of internal communication relatively. Hotel $\mathrm{C}$ also do not do well in the aspect of participating in management. For hotel B, the staff satisfaction on salary and welfare is low relatively. In addition, the satisfaction on the space of further development is not high, and the hotel also do not well in training work for internal staff.

\section{THE INTERNAL MARKETING SERVICE OF IMPROVING} INTERNAL EMPLOYEE SATISFACTION
There will not be satisfied customers without satisfied employees, if hotel wants to increase amount of customers ,it must firstly do a good job in internal service marketing to improve its own internal employee satisfaction, then it has the opportunity to attract more customers, create greater benefits for themselves.

\section{A. Building enterprise culture}

Enterprise culture is setting up when the enterprise solve the problem of survival and development and, be considered effective and sharing by members, and it is the basic faith and knowledge to be followed. Enterprise culture make enterprise employees identify enterprise's goal, conduct and values through edifying the worker. Good enterprise culture can increase the cohesion of the enterprise, can make the staff service for the enterprise consciously. Internal marketing is to establish a peopleoriented corporate culture, put the staff in primacy, all starting from the needs of employees. To make the enterprise goal is consistent with the employee goals.

It can be seen from the above analysis, the evaluation of hotel D culture is low, and the hotel D should set up its corporate culture through training or a staff meeting. The other three hotels should also be on the basis of the original to maintain or improve their own corporate culture, now many of the hotel employees know little of their hotel enterprise culture, don't know what is the hotel, don't know what is its corporate culture, as a result, will they will lack the sense of belonging in their work hotel, eventually resulting in the loss of the hotel's internal staff.

\section{$B$. Improve salary and welfare}

It is not hard to see, the score of salary and welfare in four hotel is not high, especially hotel A and hotel C. salary and welfare is concerned by every employee, is also one of the key factors of employee satisfaction. It is a basic guarantee to each employee for food and clothing live line. Hotel's workload is very big, the low salary and welfare will let staff feel dissatisfied. So, the hotel should improve its salary and welfare appropriately in order to improve its internal employee satisfaction, make them work for the hotel preferably, generate more revenue. In addition, the hotel can motivate the staff through giving employees who have good performance in work material rewards, then improve employee satisfaction.

Hotel should raise wages appropriately, the same time offer insurance for their employees, this will increase the safety of staff and the sense of belonging to the hotel, which reduces the loss of staff, avoids some unnecessary loss. In addition to these, the hotel can also improve the staff's working environment, such as staff locker room, toilet, etc. Imagine that if a staff go to work fulling of enthusiasm, firstly go to the dressing room, if the dressing room's temperature is very low, no heating, and the light is very dark, and also very wet, it must affect the enthusiasm of his work. So pay bonuses just one aspect, the hotel should think more about what they need from the perspective of employees .

\section{Strengthening staff training}

Hotel A's score of training in four hotel is the lowest among the four hotels. so the hotel A should strengthen the training for internal employees, the other three hotels should also continue to offer effective training for their staff. 
Staff's professional quality and personal ability are different, so hotel should improve the overall quality of employees through training staff, establish the concept of "customer first", and enhance the staff's service consciousness. Training includes professional ethics training, knowledge training, skills training, quality training. Through comprehensive training, the staff's professional ethics and the professional skills can be improved. So, in the daily work, they can play their professional skills and talents, so as to offer better service for hotel. Through training, it also can make employees know more about this hotel's goals and their own goals in life,make employees more initiative in learning, it also can mobilize the enthusiasm of the employees to work. In addition, the hotel can also offer similar post training to employees, it not only can reduce employee boredom of daily repetitive work, the more the main is that once the temporary leave, but also the hotel can arrange other trained person to take the employees who leave in a sudden, absences won't happen in the hotel.

D. Appropriate authorization, let employees participate in management

When the staff master professional skills, you can put some rights properly delegated to the staff, at the same time, let them participate in the management work, offer advice for the hotel.so it can increase their working enthusiasm, exert their creativity,mobilize their subjective initiative. To a certain extent, it also improve the working efficiency.

The grade of participate in the management in four hotel is not high, especially hotel $\mathrm{C}$, the hotel $\mathrm{C}$ can give a meet periodically to let employees have the opportunity to participate in, and put forward the shortage of the hotel, how to improve and so on. It will improve greatly staff's work enthusiasm, help the development of the hotel actively, the hotel director can take some good opinions.

\section{E. Establish good communication channels}

Effective communication is the key to the hotel's internal marketing, communication includes not only the horizontal communication, but also the supervisor communication in the hotel, not only including the communication between hotel and customers, but also includes the hotel internal communication between different departments. If there is no good communication in the hotel, the leader don't know what their employees need, cannot meet the needs of employees, employee satisfaction will not be high. In turn, employees can not have a better understanding of the hotel goals, business philosophy. They won't be able to work better for the hotel, the collaboration between departments also can't be very well and .So communication is important in the hotel. Among the four restaurants, hotel C'staff give the lowest score of communication, hotel $\mathrm{C}$ should consider more about how to set up some effective communication channels, such as internal journals, web site, publicity column, regular meetings, etc.

\section{F. Planing Reasonable development goals for staffs}

Easy to see, the four hotels' employees don't mark high for the employees of the development, the situation of the staffs in the hotel runs off seriously, the main reason is unchanging work every day. They can't see the hope of the development in the future,especially for the young. So, the staffs' running off is frequent. It's demanded that hotel should make the reasonable development goals for the staffs, let them have their own development space.The hotel may set up promotion mechanism to make the staffs have the hope to the future.It will make the staff have the positive attitude to the difficult work,learn the necessary skills independently, improve the work of productiveness and quality.

\section{CONCLUSION}

Staff is very important for the hotel, it is a valuable resource, it is the creator of hotel revenue. Only the hotel meet the needs of employees firstly, then the staff work hard, produce satisfied customers. So, this paper argues that the hotel managers carry out the external marketing, at the same time they should carry out the internal marketing activities to improve the internal service quality. They should analysis what employees need carefully, how to satisfy employees, such as building corporate culture, improving the salary, benefits, providing training for employees, giving proper power to employees, enhancing internal communication, planning reasonable future development goals for the employees. Do something useful to improve employee satisfaction, and thus enhance the competitiveness of the hotel service, create more revenue.

\section{REFERENCES}

[1] Xiafang Chen, Strengthening Enterprise Internal Marketing, Chinese Business, 2010(2).

[2] Guoqing Guo, Service marketing management, Service marketing management, 2011.

[3] Xuefeng Zhang, Application of principal component analysis based on SPSS in economic evaluation, Modern Business Trade Industry, no.11, pp.28-29, 2010.

[4] Kefang Li, The Key Point of Success Service in Enterprise Internal Marketing, Economic Research Guide, 2010 (3)

[5] Lovelock C.H, Patterson, P.G and Wortz J Services Marketing - An Asia - Pacific and Australian Perspective [M] . 5thedition, Pearson Australia, 2011.

[6] Rudman, R. Human Resource Management In New Zealand [M] , 5th edition, Pearson Education New Zealand, 2010.

[7] Rudman, R. Human Resource Management In New Zealand [M], 4th edition, Pearson Education New Zealand, 2007.

[8] Varoglu, D. and Eser, Z. How Service Employees Can Be Treated as Internal Customers in Hospitality Industry, Cambridge [M] , The Business / review, 2006.

[9] Bin Dai, A Study on Job Satisfaction of Deluxe Hotel Employees:Based on a Survey of the First Patch of Platinum Five Stared Hotels, Tourism Science, vol.21, no.4, 2007

[10] Rongrong Qu, Analysis based on the Internal Marketing Star Hotel Employee Satisfaction Article in A Conference Proceedings, Journal Of Liaoning Provincial College Of Communications, vol.13 no. 2,2011 